\title{
Valvular heart disease - is there still room for invasive hemodynamic evaluation
}

\author{
DMatias Trbušić1,2 ${ }^{\text {, }}$ \\ DNikola Bulj ${ }^{1,2}$, \\ DOzren Vinter ${ }^{2}$, \\ DIvo Darko Gabrić2 \\ (D)Marko Boban², \\ (iD)iana Delić- \\ Brkljačić1,2
}

'University of Zagreb School of Medicine, Zagreb, Croatia ¿University Hospital Centre „Sestre milosrdnice“, Zagreb, Croatia

\section{RECEIVED:}

July 29, 2021

ACCEPTED:

August 5, 2021

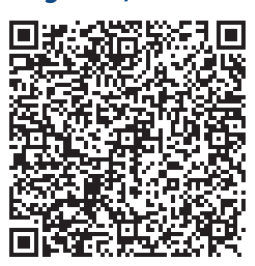

$\square$ Cardiologia Croatica 2021;16(9-10):310.
KEYWORDS: Invasive hemodynamic evaluation, right-sided heart catheterization, valvular heart disease.

CITATION: Cardiol Croat. 2021;16(9-10):310. | https://doi.org/10.15836/ccar2021.310

*ADDRESS FOR CORRESPONDENCE: Matias Trbušić, Klinički bolnički centar Sestre milosrdnice, Vinogradska 29, HR-10000 Zagreb, Croatia. / Phone: +385-91-5062-986 / Email: matias.trbusic@gmail.com

ORCID: Matias Trbušić, https://orcid.org/0000-0001-9428-454X • Nikola Bulj, https://orcid.org/0000-0002-7859-3374 Ozren Vinter, https://orcid.org/0000-0002-4236-7594 • Ivo Darko Gabrić, https://orcid.org/0000-0003-4719-4634 Marko Boban, https://orcid.org/0000-0002-6129-575X • Diana Delić-Brkljačić, https://orcid.org/0000-0002-7116-2360

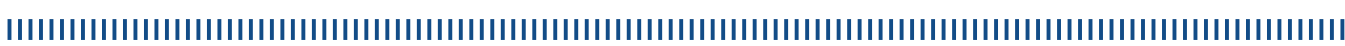

The development of echocardiographic methods and magnetic resonance for the evaluation of heart structure and function raises the question of the role of right-sided heart catheterization (RHC) or invasive hemodynamic evaluation (IHE) in valvular heart diseases. According to current guidelines, this method occupies a peripheral role and is reserved for situations where non-invasive testing is non-inclusive or discordant with clinical status ${ }^{1}$. As pulmonary hypertension (PH) is one of the criteria for surgery in asymptomatic aortic stenosis and mitral regurgitation (MR), it is especially important to measure it accurately. However, non-invasive measurement of PH based on echocardiography has its limitations and the possibility of error and is particularly problematic in the presence of severe tricuspid regurgitation (TR) and reduced right ventricular (RV) function. A typical example where this is particularly important is persistent severe TR after mitral valve surgery leading to dilatation and dysfunction of the RV. Cardiac reoperation carries an increased risk, but it is considered in the absence of left-sided valve dysfunction, severe RV or left ventricular (LV) dysfunction and severe pulmonary vascular resistance/hypertension where RHC plays a key role ${ }^{1}$. A particular problem for cardiac evaluation is multiple and mixed valvular heart disease, especially in the presence of some other heart pathology such as coronary heart disease, LV dysfunction or constriction ${ }^{2}$. Exercise RHC is becoming increasingly popular in the diagnosis of heart failure with preserved systolic function, and now it is a question of its role in the diagnosis of valvular disease as well. The test has the potential to predict a worse outcome and thus for earlier surgery in asymptomatic patients e.g. with aortic stenosis or $\mathrm{MR}^{3}$. In conclusion, IHE is a useful and relatively harmless tool in the examination of valvular heart disease, but experience of cardiology teams is needed to get a true benefit of the method and to avoid misleading information. Gaining experience requires hard work perhaps even in cases where IHE is not fully indicated.

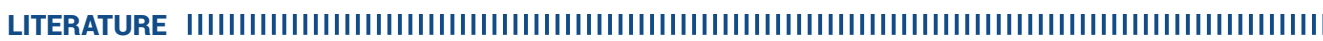

1. Baumgartner H, Falk V, Bax JJ, De Bonis M, Hamm C, Holm PJ, et al; ESC Scientific Document Group. 2017 ESC/EACTS Guidelines for the management of valvular heart disease. Eur Heart J. 2017 Sep 21;38(36):2739-2791. https://doi.org/10.1093/eurheartj/ehx391

2. Unger P, Pibarot P, Tribouilloy C, Lancellotti P, Maisano F, lung B, et al; European Society of Cardiology Council on Valvular Heart Disease. Multiple and Mixed Valvular Heart Diseases. Circ Cardiovasc Imaging. 2018 Aug;11(8):e007862. https://doi.org/10.1161/CIRCIMAGING.118.007862

3. Hein M, Neu JN, Dorfs SD, Doerken SD, Zeh WZ, Neumann NJ, et al. Invasive exercise hemodynamics in patients with severe primary mitral regurgitation and preserved ejection fraction predicts future valve surgery. Eur Heart J. 2020 Nov; 41(Suppl 2): ehaa946.1905. https://doi.org/10.1093/ehjci/ehaa946.1905 